\title{
Inmunodiagnóstico de la fasciolosis humana en la provincia de Chupaca-Junin, mediante un ELISA de captura basado en cistatina
}

\author{
WILLIAM CORNEJO ${ }^{1}$, PILAR ALVA ${ }^{1}$, CARLOS SEVILLA ${ }^{1}$, ALINA HUIZA ${ }^{1,2}$ \\ ${ }^{1}$ Departamento Académico de Microbiología Médica. ${ }^{2}$ Instituto de Medicina \\ Tropical "Daniel A. Carrión”, Facultad de Medicina-UNMSM.
}

\begin{abstract}
RESUMEN
OBJETIVO: Determinar la prevalencia de fasciolosis humana en un área endémica mediante un inmunoensayo enzimático (ELISA) que emplea la cistatina como agente de captura para la detección de anticuerpos específicos para cisteinil proteinasas de Fasciola hepatica. MATERIAL Y MÉTODOS: Una placa de ELISA fue sensibilizada con cistatina, incubada con los productos de excreción-secreción del parásito adulto, seguido del procedimiento estándar para la prueba. La aplicación del ELISA de captura para el inmunodiagnóstico de la fasciolosis consideró el estudio de 200 muestras de suero de niños y adultos de la provincia de Chupaca, en el departamento de Junín. RESULTADOS: Las muestras de suero provenientes de una población endémica evaluada por la prueba de ELISA de captura revelaron 27/200 (13,5\%) casos positivos. CONCLUSIÓN: La fasciolosis constituye un problema de salud importante en la provincia de Chupaca, departamento de Junín.
\end{abstract}

Palabras clave: Fascioliasis; fasciola hepática; ELISA; tests inmunológicos.

\section{CYSTATIN CAPTURE ELISA IMMUNODIAGNOSIS OF HUMAN FASCIOLOSIS AT CHUPACA-JUNIN PROVINCE \\ SUMMARY}

OBJECTIVE: To determine the prevalence of human fasciolosis in an endemic area by means of an enzyme-linked immunosorbent assay (ELISA) using cystatin as a capture agent for the detection of specific antibodies to Fasciola hepatica cysteine proteinases. MATERIAL AND METHODS: An ELISA plate was sensitized with cystatin, incubated with excretory-secretory products of adult flukes, and followed by standard ELISA procedures. Clinical applicability of the cystatin capture ELISA for the immunodiagnosis of fasciolosis was tested with 200 serum samples of children and adults from an endemic area in Chupaca province, Junin department. RESULTS: Serum samples from the endemic area tested by cystatin capture ELISA showed 27/ $200(13,5 \%)$ of positive cases. CONCLUSIONS: Fasciolosis remains a major health problem at Chupaca province, Junin department.

Key word: Fascioliasis; fasciola hepatica; enzyme-linked inmunosorbent assay; immunologic tests.

\footnotetext{
Correspondencia:

Blgo. William Cornejo Medina

Instituto de Medicina Tropical "Daniel A. Carrión"

UNMSM - Servicio de Inmunología.

Jr. José Santos Chocano 199. Urb. San Joaquín

Callao 02, Perú

E-mail: wcormed@hotmail.com
} 


\section{INTRODUCCIÓN}

La fasciolosis es una zoonosis producida por Fasciola hepatica, tremátodo parásito que al estadio adulto se localiza en los conductos biliares del hígado de mamíferos domésticos, causando pérdidas económicas serias debido a la disminución en la productividad de vacunos, ovinos, caprinos y camélidos infectados $\left(^{1}\right)$. El hombre puede adquirir la infección por el consumo de alimentos vegetales contaminados con la metacercaria . La fasciolosis humana es considerada un problema de salud pública en Perú, Bolivia, Chile y Ecuador, debido a que la infección es endémica $\left(^{2}\right)$. Una alta prevalencia de fasciolosis humana ha sido reportada en el altiplano boliviano mediante el examen coproparasitológico $\left({ }^{3}\right)$. Estudios similares efectuados en los valles del Mantaro y Cajamarca reportan tasas de infección entre 10 y $15 \%$ en niños y entre 13 y $14 \%$ en adultos $\left({ }^{4-6}\right)$.

El diagnóstico habitual de la fasciolosis humana se realiza a través del examen parasitológico de heces $\left({ }^{7}\right)$, por inmunoelectroforesis $\left({ }^{8}\right)$ o por ambos métodos. El inmunodiagnóstico de la infección humana ha sido mejorado al emplearse pruebas inmunoenzimáticas que usan antígenos somáticos, metabólicos o moléculas purificadas del parásito $\left.{ }^{(9-12}\right)$. De los antígenos purificados, las cisteinil proteinasas han permitido obtener una buena sensibilidad y especificidad del ELISA para fasciolosis $\left({ }^{11-13}\right)$. Sin embargo, la principal limitación en la obtención de las proteinasas es el empleo de equipo y procedimientos especializados $\left({ }^{11,14,15}\right)$. Recientemente se ha desarrollado un ELISA que utiliza cistatina como agente de captura de cisteinil proteinasas, el cual pudo detectar anticuerpos específicos para dichas proteinasas sin tener que purificarlas $\left({ }^{16}\right)$.

En el presente estudio empleamos la prueba de ELISA de captura con cistatina para determinar la prevalencia de la fasciolosis en la provincia de Chupaca, departamento de Junín.

\section{MATERIAL Y MÉTODOS}

Se colectó 200 muestras de suero de niños y adultos asintomáticos de la provincia de Chupaca, departamento de Junín, quienes accedieron voluntariamente, con consentimiento informado, a ser evaluados. Del total de estas muestras, 42 sueros fueron de adultos provenientes del personal y familiares del Centro de Salud de Chupaca y 159 sueros fueron de escolares del Centro Educativo "19 de Abril". Los sueros fueron congelados a $-20^{\circ} \mathrm{C}$ hasta su uso.

La estandarización de la prueba ELISA de captura basado en cistatina se basó en el procedimiento descrito con anterioridad $\left({ }^{16}\right)$, con algunas modificaciones. La densidad óptica fue medida a $492 \mathrm{~nm}\left(\mathrm{DO}_{492 \mathrm{~nm}}\right)$, en un lector de micro-ELISA (Multiskan plus versión 2,01).

\section{RESULTADOS}

Se evaluó 200 muetras de suero, de las cuales 105 fueron de personas del sexo maculino y 92 del sexo femenino. De las 159 muestras de suero de los escolares, 89 fueron varones y 70 mujeres, cuyas edades estuvieron entre 12 y 18 años de edad.

La prueba de ELISA reveló 27/200 (13,5\%) de casos positivos. Trece fueron del sexo femenino y 14 del sexo masculino; 21 casos positivos correspondieron a la población escolar y el resto a los voluntarios adultos.

\section{DISCUSIÓN}

La aplicación del ELISA de captura basado en cistatina en una población adulta y escolar de la Provincia de Chupaca reveló 13,5\% de casos positivos. Si bien la epidemiología de la fasciolosis humana ha cambiado, habiéndose registrado una disminución en el número de casos en la zona de estudio $\left({ }^{17,18}\right)$, otros trabajos dan cuenta de una mantención o incluso de un aumento en la prevalencia de fasciolosis en áreas 
endémicas como el valle del Mantaro, Junín $\left({ }^{19}\right)$, demostrada no solamente por métodos coprológicos sino también serológicos. Mas aún, la prevalencia por métodos serológicos utilizando un ELISA que emplea como antígeno una cisteinil proteinasa (Fas2-ELISA) fue marcadamente mayor a la encontrada por métodos coproparasitológicos $(32,5 \%$ vs. $20,6 \%)\left({ }^{19}\right)$. La prueba de ELISA de captura ha sido previamente evaluada por Ikeda $\left({ }^{16}\right)$, quién encontró 9/9 casos positivos de fasciolosis diagnosticada parasitológicamente y escasa reactividad cruzada con otras parasitosis. Nosotros hemos encontrado una sensibilidad del $92 \%$ y una especificidad del 97\% (datos no mostrados) para la prueba. Aunque la presencia de anticuerpos específicos indica exposición al parásito, pero no necesariamente una infección activa, la prevalencia encontrada refleja la importancia que alcanza la infección por $F$. hepatica en el área estudiada.

El alto porcentaje de infección por $F$. hepatica encontrada demuestra que la Provincia de Chupaca es aún un área endémica para la infección por el parásito.

\section{AGRADECIMIENTOS}

A la Dra. Pilar Díaz Valer, Directora del Centro de Salud de Chupaca, por las facilidades brindadas en el trabajo de campo.

Este trabajo fue financiado por el Consejo Superior de Investigación de la UNMSM. Código: 000101241.

\section{BIBLIOGRAFÍA}

1. Hillyer GV. Fascioliasis, Paragonimiasis, Clonorchiasis, and Opisthorchiasis. Walls KW, Schantz PM, eds. Immunodiagnosis of parasitic diseases. Vol. 1, Helminthic diseases. Academic Press, Inc. 1986.

2. Chen MG, Mott E. Progress in assesment of morbidity due to Fasciola hepatica infection: a review of recent literature. Trop Dis Bull 1990; 87: R1-R38.

3. Esteban JG, Flores A, Angles R, Strauss W, Aguirre C, Mas-Coma S. A population-based coprological study of human fascioliasis in a hyperendemic area of the Bolivian Altiplano. Trop Med Int Health 1997; 2: 695-9.
4. Bendezú P. Algunos aspectos de la epidemiología de la distomatosis hepática y su control biológico en el valle del Mantaro. Bol Extr IVITA, UNMSM 1970; 4: 356-67.

5. Náquira $\mathbf{C}$, Náquira $\mathbf{F}$, Alemán $\mathbf{C}$, et al. Distomatosis hepática humana en dos localidades del valle del Río Mantaro. Rev Per Med Trop UNMSM 1972; 1: 33-7.

6. Leguía G. Distomatosis hepática en el Perú: epidemiología y control. Hoechst. Lima. 1988.

7. Lumbreras H, Cantella R, Burga R. Acerca de un procedimiento de sedimentación rápida para investigar huevos de Fasciola hepatica en las heces, u evaluación y uso en el campo. Rev Med Per 1962; 31: 167-74.

8. Capron A, Biguet J, Tran Van Ky, Rose G. Posibilites nouvelles dans le diagnostic immunologique de la ditomatose humaine à Fasciola hepática. Mise en evidence d'anticorps sériques par immunoelectrophorèse. Presse Medicale 1964; 72: 3101.

9. Knobloch J. Human fascioliasisin Cajamarca/Perú. Trop Med Parasitol 1985; 36: 91-3.

10. Espino AM, Dumenigo BE, Fernández R, Finlay CM. Immunodiagnosis of human fascioliasis by enzyme-linked immunosorbent assay using excretory-secretory products. Am J Trop Med Hyg 1987; 37: 605-8.

11. Yamasaki H, Aoki T, Oya H. A cysteine proteinase from the liver fluke Fasciola spp.: purification, characterization, localization and application to immunodiagnosis. Jpn J Parasitol 1989; 38: 373-84.

12. Córdova M, Reategui L, Espinoza JR. Immunodiagnosis of human fascioliasis with Fasciola hepatica cysteine proteinases. Trans R Soc Trop Med 1999; 93: 54-7.

13. O'Neill SM, Parkinson M, Dowd AJ. Short report: Immunodiagnosis of human fascioliasis using recombinant Fasciola hepatica cathepsin L1 cysteine proteinase. Am J Trop Med Hyg 1999; 60: 749-51.

14. Cordova M, Herrera P, Nopo L, Bellatin J, Naquira C, Guerra H, et al. Fasciola hepatica cysteine proteinases: immunodominant antigens in human fascioliasis. Am J Trop Med Hyg 1997; 57: 660-6.

15. Rege AA, Herrera RP, Lopez M, Dreden MH. Isolation and characterization of a cysteine proteinase from Fasciola hepatica adult worms. Mol Biochem Parasitol 1989; 35: 89-96.

16. Ikeda T. Cystatin capture enzyme-linked immunosorbent assay for immunodiagnosis of human paragonimiasis and fascioliasis. Am J Trop Med Hyg 1989; 59: 286-90.

17. Contreras O, Huiza A, Náquira F. Enteroparasitismo en escolares de la Provincia de Chupaca-Junín. En: Libro de resúmenes, 2do. Congreso Peruano de Parasitología, 1-5 de Julio de 1995, Trujillo-Perú, p. 18.

18. Espinoza Y, Alva P, Huiza A, et al. Enteroparasitismo en Chupaca-Junín. En: Libro de resúmenes del IV Congreso Peruano de Parasitología, 22-24 de Septiembre del 2000, Lima-Perú, p. 106.

19. Marcos L, Maco V, Terashima A, et al. Hiperendemicidad de fasciolosis humana en el valle del Mantaro, Junín: análisis epidemiológico. Rev Med Herediana 2001; 12 (Supl 1): 15. 